\title{
Isolated right ventricular infarction: Fatal dissection and shock requiring invasive therapies
}

\author{
Amber Makani, Claire Sullivan, Richard Josephson \\ University Hospitals Case Medical Center, Cleveland, $\mathrm{OH}$, USA
}

Received: May 7, 2016

Accepted: July 20, 2016

Online Published: August 1, 2016

DOI: $10.5430 /$ crim.v3n4p1

URL: http://dx.doi.org/10.5430/crim.v3n4p1

\begin{abstract}
A 78-year-old female with a history of dyslipidemia and hypertension presented with chest tightness and pain. On presentation she was noted to be hypertensive with ECG significant for ST elevation in leads II, III, aVF, as well as leads V2-V6. Coronary angiogram indicated $99 \%$ stenosis of the right coronary artery (RCA); however, within hours of receiving a drug eluting stent to the diseased artery, the patient had recurrent chest pain concerning for in-stent thrombosis. The catheterization was complicated by complete heart block, coronary artery dissection, and subsequently cardiogenic shock. The extent of this patient's morbidity and ultimately mortality caused by isolated right ventricular myocardial infarction secondary to single vessel disease, despite aggressive interventional life support makes this case unique.
\end{abstract}

Key Words: Right ventricular infarct, Ischemia, Infarct, Mechanical support

\section{INTRODUCTION}

Despite significant advances in prevention and treatment, cardiovascular disease continues to be the major cause of morbidity and mortality in the developed world, causing greater mortality than cancer, respiratory disease and accidents combined. ${ }^{[1]}$ Acute coronary syndrome may present as an acute myocardial infarction (MI), which may or may not be associated with ST-elevation noted on EKG, or unstable angina. While inferior MI infarction without right ventricular (RV) involvement has approximately $6 \%$ mortality, associated RV infarction has an in-hospital mortality of 31\%. ${ }^{[2]}$ RV MIs are relatively small in comparison to left ventricular ischemia, as the RV is often perfused by both the right and left coronary arteries allowing the most of the infarcted myocardium to remain viable even in the absence of reperfusion interventions ${ }^{[3]} \mathrm{RV}$ infarctions are associated with inferior wall ischemia in up to fifty percent of cases. ${ }^{[3]}$ Effects of a
RVMI can range from minimal sequelae no hemodynamic changes to hypotension and cardiogenic shock. We report a right ventricular myocardial infarction case that was lethal despite aggressive intervention.

\section{Case presentation}

A 78-year-old-female with a history of dyslipidemia and hypertension presented to an outside hospital with chest pain. Notably she was not taking any medications and had no history of tobacco or alcohol use. Vital signs on presentation indicated a blood pressure of 174/85 with a heart rate of 63 . The patient's oxygen saturation was $99 \%$ on $4 \mathrm{~L}$ of $\mathrm{O}_{2}$. ECG suggested an inferior STEMI (see Figure 1) and the patient was taken directly to the catheterization lab. Coronary angiography showed $99 \%$ heavily calcified stenosis of the ostial right coronary artery (RCA). Rotablation was performed and a drug-eluting stent (DES) was placed. Within several hours

\footnotetext{
*Correspondence: Amber Makani, MD; Email: amber.makani@uhhospitals.org; Address: University Hospitals Case Medical Center, Cleveland, $\mathrm{OH}$, USA.
} 
after the completion of the procedure, the patient developed recurrent chest pain and was taken back to the catheterization lab for concern of in-stent thrombosis. Percutaneous transluminal coronary angioplasty (PTCA) was performed at this time; however, this catheterization was complicated by complete heart block, which required a temporary pacemaker, as well as cardiogenic shock for which an intra-aortic balloon pump (IABP) was placed and norepinephrine was started. Coronary angiography noted that the RCA was extensively dissected (see Figure 2) during the second catheterization. During this time, the patient developed profound hypoxia requiring intubation and mechanical ventilation and she was transferred to the cardiac intensive care unit at our facility.

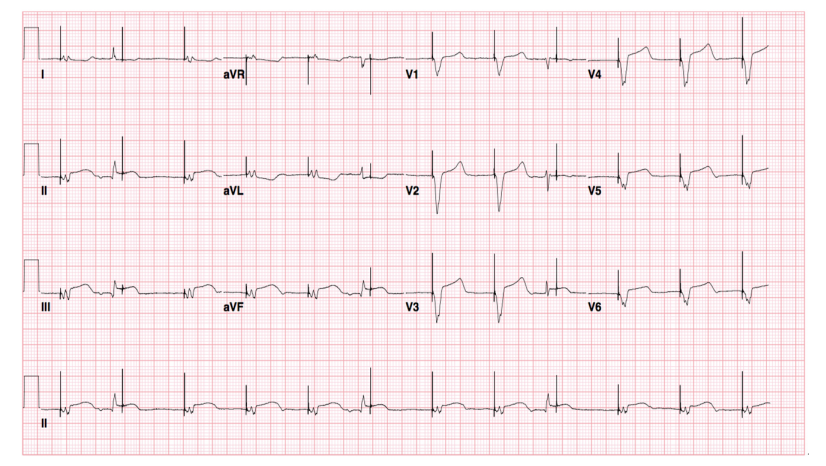

Figure 1. EKG indicating ST-elevation in leads II, III, aVF, V2-V6 (paced rhythm)

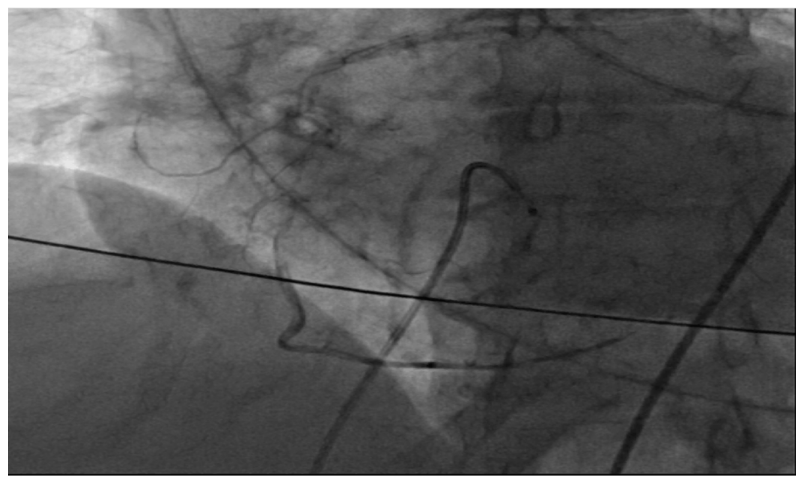

Figure 2. Wire out shot of RCA showing dye staining representative of extensive RCA dissection

On arrival to the ICU, vitals sings indicated a BP of $117 / 54$, heart rate of 71. The patient was noted to have $\mathrm{O}_{2}$ sats of $80 \%$ on $100 \% \mathrm{FiO}_{2}$ with an arterial blood gas indicating $\mathrm{pH} 7.24, \mathrm{pCO}_{2} 30, \mathrm{pO}_{2} 58$ with a bicarbonate level of 20 on renal function labs suggesting severe metabolic acidosis. Patient received a right heart catheterization (RHC) with leave-in Swan Ganz catheter indicating right atrial (RA) pressure mean $18 \mathrm{mmHg}$, pulmonary artery pressure (PAP) $29 \mathrm{mmHg} / 18 \mathrm{mmHg}$, pulmonary capillary wedge pressure
(PCWP) $12 \mathrm{mmHg}$, and cardiac output (CO) $2.88 \mathrm{~L} / \mathrm{min}$ and cardiac index $(\mathrm{CI}) 1.47 \mathrm{~L} / \mathrm{min} / \mathrm{m}^{2}$. Oxygen saturations were noted to be superior vena cava $30 \%$, pulmonary artery $26 \%$. Transthoracic echocardiogram revealed a small, underfilled LV, overall preserved systolic function, moderate tricuspid regurgitation, RV apex with preserved contractility, akinetic base and free wall of RV, and a large right to left shunt (see Figure 3). Cardiothoracic surgery was consulted for extracorporeal membrane oxygenation (ECMO) and right ventricular assist device (RVAD) and the patient was taken to the OR for A-V ECMO and 1 vessel coronary artery bypass grafting with saphenous vein graft to the right coronary artery. Several days later, she was taken back to the OR for RVAD placement. Unfortunately in the post-operative period, the patient developed multi-organ system failure with substantial bleeding from chest tube sites as well as hemodynamically significant atrial fibrillation. The family elected to withdraw care and the patient passed away shortly thereafter.

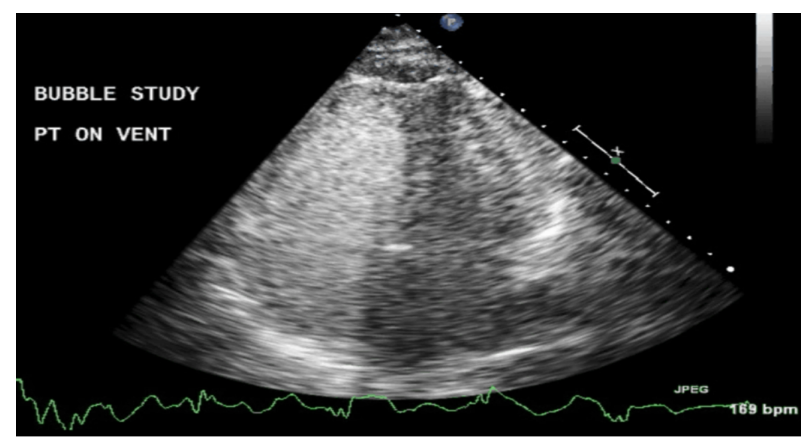

Figure 3. Transthoracic echocardiogram (TTE) apical four chamber view depicted above. TTE revealed a small, underfilled LV, overall preserved systolic function, moderate tricuspid regurgitation, RV apex with preserved contractility, akinetic base and free wall of RV, and a large right to left shunt

\section{Discussion}

RVMI is generally associated with left ventricular (LV) infarction, with isolated RVMI being rare in occurrence. Several factors contribute to the relative infrequency of isolated $\mathrm{RV}$ infarct including extensive collaterals, smaller muscle mass and relatively decreased oxygen requirement of the RV due to lower workload. ${ }^{[3]}$ Clinical presentation from RV infarction can vary greatly from mild hypotension to cardiogenic shock, but usually includes the triad of distended neck veins, hypotension, and lungs that are clear to auscultation. The differential diagnosis for this presentation includes pulmonary embolism, cor pulmonale, pulmonary hypertension, tricuspid regurgitation, pericarditis, and hypertrophic or restrictive cardiomyopathy. However, prompt recognition of ischemic cause is imperative as reperfusion of the RCA can 
dramatically improve RV function and hemodynamics. ${ }^{[4]}$

In cases where acute RV infarct is suspected, right-sided precordial leads are helpful for evaluation in the early course of disease. ST elevation in the V4R lead has been shown to have $93 \%$ sensitivity and $95 \%$ specificity for RV involvement. ${ }^{[5]}$ Echocardiogram generally indicates RV dilatation, RV wall motion abnormalities, and tricuspid regurgitation. $\mathrm{RV}$ pressures are generally found to be elevated in proportion to LV pressures. Criteria for RV infarction include RA pressures greater than $10 \mathrm{~mm} \mathrm{Hg}$ and RA to pulmonary capillary wedge pressure ratio that is greater than $0.8 .^{[6]}$ The high right sided pressure stimulates secretion of atrial natriuretic peptide (ANP), a potent vasodilator, diuretic, and aldosterone inhibitor. This effect, in addition to impaired systolic function and decreased diastolic compliance causes patients to be volume sensitive and sensitive to preload reducing agents such as morphine, diuretics, and nitrates. ${ }^{[7]}$ In cases of severe infarction where RV contractility is diminished and afterload is increased, elevated right atrial pressure is the main driving force and thus, increasing preload with significant fluid repletion is the mainstay in temporarily stabilizing patients prior to revascularization. ${ }^{[8]}$ In confirmed cases of RV infarc- tion, unexplained hypoxia despite the administration of $100 \%$ oxygen should raise the suspicion for right-to-left shunting in the atria in the presence of RV failure and elevated RA pressures. ${ }^{[9]}$

With regard to therapeutic intervention, PCI has been shown to have decreased three-day in hospital mortality rates in comparison to thrombolytic agents. ${ }^{[10]}$ In patients with RV infarct and significant hemodynamic compromise, such as our patient, intraaortic balloon pumps and left-sided impellas have limited success given right-sided pump failure. $\mathrm{Al}-$ though current research is limited, in patients with severe cardiogenic shock, RVAD and newly FDA-approved right sided impellas have been shown to have utility in increasing hemodynamic stability. ${ }^{[8]}$ Overall studies have shown that patients presenting with acute MI who develop cardiogenic shock due to RV have increased in-hospital mortality and complications in comparison to those presenting with shock secondary to LV failure with a $5 \times$ increase in 3-day mortality. ${ }^{[11]}$

\section{CONFLICTS OF INTEREST Disclosure}

The authors have declared no conflicts of interest.

\section{REFERENCES}

[1] Roger VL, Go AS, Lloyd-Jones DM, et al. Heart disease and stroke statistics-2011 update: a report from the American Heart Association. Circulation. 2011; 123(4): e18-e209. PMid:21160056 http://dx.doi.org/10.1161/CIR.0b013e3182009701

[2] Bowers TR, O'Neill WW, Grines C, et al. Effect of reperfusion on biventricular function and survival after right ventricular infarction. N Engl J Med. 1998; 338: 933. PMid:9521980 http: //dx.doi.org/10.1056/NEJM199804023381401

[3] Ondrus T, Kanovsky J, Novotny T, et al. Right ventricular myocardial infarction: From pathophysiology to prognosis. Exp Clin Cardiol. 2013; 18(1): 27-30. PMid:24294033

[4] Lim S, Goldstein JA. Curr Treat Options Cardio Med. 2001; 3: 95. http://dx.doi.org/10.1007/s11936-001-0065-y

[5] Haji SA. Right Ventricular Infarction Diagnosis and Treatment. Clinical Cardiology. 2000; 23: 473-482. PMid:10894433 http: //dx.doi.org/10.1002/clc.4960230721

[6] Sugiura T, Iwasaka T, Shiomi K, et al. Clinical significance of right ventricular dilatation in patients with right ventricular infarction. Coron Artery Dis. 1994; 5(12): 955-9. PMid:7728295 http://dx.doi.org/10.1097/00019501-199412000-00001
[7] Mittal SR. Isolated right ventricular infarction. Int J Cardiol. 1994; 46(1): 53-60. http://dx.doi.org/10.1016/0167-5273(94) 9 0117-1

[8] Arrieta-Garcia C, Klein L. Right Ventricular Assist Devices in Right Ventricular Infarction: Do They Augment Right Ventricular Function Sufficiently to Improve Prognosis? J Invasive Cardiol. 2011; 23(6). PMid:21646653

[9] Pfisterer M, Emmenegger H, Müller-Brand J, et al. Prevalence and extent of right ventricular dysfunction after myocardial infarctionrelation to location and extent of infarction and left ventricular function. Int J Cardiol. 1990; 28(3): 325-32. http://dx. doi .org/10. 1016/0167-5273(90) 90315-V

[10] Lupi-Herrera E, González-Pacheco H, Juárez-Herrera U, et al. Primary reperfusion in acute right ventricular infarction: An observational study. World J Cardiol. 2014; 6(1): 14-22. PMid:24527184 http://dx.doi.org/10.4330/wjc.v6.i1.14

[11] Jacobs AK, Leopold JA, Bates E, et al. Cardiogenic shock caused by right ventricular infarction: A report from the SHOCK registry. J Am Coll Cardiol. 2003; 41: 1273-9. http://dx.doi.org/10.1016/S 0735-1097 (03) 00120-7 